Published in final edited form as:

Heart Fail Clin. 2010 April ; 6(2): 215-222. doi:10.1016/j.hfc.2009.11.007.

\title{
Heart Failure and Pulmonary Hypertension
}

\author{
Jordan T. Shin, MD, $\mathbf{P h D}^{1,2}$ and Marc J. Semigran, MD $^{2}$ \\ ${ }^{1}$ Cardiovascular Research Center, Massachusetts General Hospital, Boston, MA \\ ${ }^{2}$ Cardiology Division, Massachusetts General Hospital, Boston, MA
}

\section{Summary}

\begin{abstract}
When PH and RV dysfunction accompany HF, the impact on functional capacity and prognosis are ominous. Newer clinical strategies to preferentially lower pulmonary pressures and pulmonary vascular tone improve functional performance and symptoms of heart failure by targeting the NO signal transduction pathways as with PDE5 inhibition. Additional studies are needed to delineate if these therapies will impact long-term patient outcomes and to elucidate the specific mechanisms whereby these treatments are effective. Furthermore, the recent finding that mutations in BMPR2 cause familial forms of PAH and that BMPR2 expression is decreased in secondary forms of PH strongly implicate BMP signaling in the underlying pathophysiology of $\mathrm{PH}$. Translation of emerging basic science insights in the vascular biology of $\mathrm{PH}$ and BMP signaling will provide novel therapeutic strategies for the spectrum of pulmonary hypertensive diseases.
\end{abstract}

\section{Keywords}

heart failure; pulmonary hypertension; nitric oxide; PDE5; BMPR2

\section{Introduction}

Heart failure (HF) is a significant and growing problem in the United States, and is predicted to afflict 1 in 5 adults over the course of their lifetime. ${ }^{1}$ It represents the most common Medicare diagnosis at hospital discharge and will account for approximately $\$ 37.2$ billion in healthcare expenditures in 2009.2 Despite major advances in therapy over the last two decades, current treatment often is palliative in nature and therapies directed at symptom management and delay of disease progression. An improved understanding of the factors that modify prognosis and outcome would be beneficial in stratifying patient risk and in developing novel therapeutic opportunities.

For any given myocardial insult, there is thought to be substantial variation in the susceptibility to developing heart failure, but the underlying factors responsible for such variation are only beginning to be understood. Inter-individual differences in many components of the response to myocardial injury have been implicated including local or remote myocardial remodeling.

\footnotetext{
Correspondence to: Jordan T. Shin.

Jordan T. Shin, MD, PhD, Cardiovascular Research Center and Cardiology Division, Massachusetts General Hospital and Harvard Medical School, $14913^{\text {th }}$ Street, Charlestown, MA 02129, jshin1@ partners.org, Tel: 617-726-9554, Fax: 617-726-4105

Marc J. Semigran, MD, Medical Director, Heart Failure and Transplantation, Cardiology Division, Massachusetts General Hospital and Harvard Medical School, GRB 800, 55 Fruit Street, Boston, MA 02114, msemigran @ partners.org, Tel: 617-726-8862, Fax: 617-726-4105

Publisher's Disclaimer: This is a PDF file of an unedited manuscript that has been accepted for publication. As a service to our customers we are providing this early version of the manuscript. The manuscript will undergo copyediting, typesetting, and review of the resulting proof before it is published in its final citable form. Please note that during the production process errors may be discovered which could affect the content, and all legal disclaimers that apply to the journal pertain.
} 
The impact of co-morbid conditions such as pulmonary hypertension (PH) is also thought to play a role in determining the course and prognosis of HF. The determinants and regulators of pulmonary vascular tone and the impact on HF are poorly characterized.

Increased pulmonary vascular tone and $\mathrm{PH}$ together with consequent right ventricular (RV) dysfunction are now known to be among the most significant modifiers of both the natural history and prognosis of HF resulting from left ventricular disease. PH in HF is thought to result from congestion and chronic pulmonary venous hypertension. PH is associated with a negative impact on survival ${ }^{3}$ and reversibility of $\mathrm{PH}$ in response to pharmacological or mechanical interventions is a predictor of improved HF outcomes.4 PH in HF may initially begin as a passive process resulting from congestion and elevated filling pressures, and pulmonary venous hypertension. With chronic congestion, pulmonary vascular tone may be become irreversibly elevated. However, the fundamental mechanisms determining pulmonary vascular responses in response to heart failure and the development of $\mathrm{PH}$ remain incompletely understood.

Recently, advances have been made in our understanding of the mechanisms underlying pulmonary arterial hypertension (PAH). In contrast to the substantial and growing burden of $\mathrm{HF}$, primary PAH is a relatively rare disease. Advances in dissecting the molecular pathogenesis of PAH hypertension have begun to illuminate some of the molecular pathways responsible for PH both in its primary and secondary forms may help provide insights into the molecular and genetic factors regulating pulmonary vascular tone. Because pulmonary tone is a powerful determinant of outcomes in HF, this understanding may provide insights into the factors that determine both the prognosis and course.

\section{Classification of Pulmonary Hypertension}

Pulmonary hypertension represents a diverse spectrum of disease. Most frequently, $\mathrm{PH}$ is associated with an underlying primary diagnoses such as congenital heart disease, scleroderma/ CREST, thromboembolic disease, chronic hypoxia, chronic obstructive pulmonary disease (COPD), as well as left heart failure. ${ }^{5}$ In the absence of an underlying etiology, PAH is termed idiopathic or primary. Primary PAH is a relatively rare disorder with an incidence of 1-2 cases per million in the US population, 6 but may offer insights into the etiology of more general diathesis towards aberrant pulmonary vascular responses. Between $10-30 \%$ of cases of primary PAH cluster in familial cohorts. These cases are autosomal dominant with low penetrance; only $10-20 \%$ of patients harboring a mutation exhibit the overt disease phenotype. 7

In 1998, the second World Symposium on Pulmonary Hypertension in Evian, France, represented the initial attempt to classify PH based on the underlying etiology. 8 The spectrum of pulmonary hypertensive diseases was divided into five clinical categories which were grouped according to therapeutic treatment interventions: a) pulmonary arterial hypertension; b) pulmonary venous hypertension; c) PH associated with disorders of the respiratory system; d) PH caused by thrombotic or embolic disease; and e) PH caused by diseases affecting pulmonary vasculature. The Third World Symposium on Pulmonary Arterial Hypertension in Vienna held in 2003 revised and extended the Evian classification scheme. ${ }^{5}$ As with the 1998 scheme, there were five categories but they were arranged somewhat differently: 1) PAH; 2) $\mathrm{PH}$ with left heart disease; 3) $\mathrm{PH}$ associated with lung diseases and/or hypoxemia; 4) $\mathrm{PH}$ due to chronic thrombotic and/or embolic disease; and 5) miscellaneous. Important changes included the recognition of $\mathrm{PH}$ associated with left heart disease as a wholly distinct category (category 2). 


\section{The Clinical Diagnosis and Evaluation of Pulmonary Arterial Hypertension}

The clinical presentation of $\mathrm{PH}$ can be relatively nonspecific and difficult to differentiate from other cardiopulmonary diseases. Based on national registry data, the most frequently recorded symptoms were dyspnea (found in $60 \%$ of patients), fatigue (19\%), and pre-syncope or syncope (13\%). Other symptoms may include chest pain, palpitations or edema. The lack of specific findings can delay the identification of a definitive diagnosis; the average interval between onset of symptoms and diagnosis was 2 years. ${ }^{9}$ Family history may offer little assistance given the relatively low prevalence and penetrance of identified mutations in PAH.

As pulmonary pressures rise and right heart failure ensues, the physical findings of $\mathrm{PH}$ become less subtle. Examination of the jugular pulsations can reveal elevated neck veins and prominent $\mathrm{v}$-waves. In the setting of more profound RV dysfunction, hepatic enlargement and pulsation, lower extremity edema and ascites may be found. Cardiac examination may also be notable for an RV heave or lift. The classic auscultatory finding is of an accentuated pulmonic component of the second heart sound (P2). Additionally, a systolic murmur of tricuspid regurgitation and a right-sided S3 may also be heard. Other notable findings include Raynaud phenomenon in $10 \%$ of patients. ${ }^{9}$

No definitive set of laboratory tests confirm the diagnosis of PH. Testing for HIV, hepatic enzymes, thyroid function testing and rheumatologic markers of auto-immune and connective tissue diseases are helpful in identifying secondary causes of PH. Measurement of serum BNP levels may be a useful correlate of hemodynamics. ${ }^{10}$

Noninvasive testing can be helpful in raising PAH in the differential and suggesting the diagnosis of $\mathrm{PH}$. While there is no pathognomonic EKG to diagnose $\mathrm{PAH}$, common electrocardiographic findings include right atrial enlargement and prominent $\mathrm{R}$-wave voltages in the inferior leads, right axis deviation and RV strain. The chest radiographic manifestations of PAH include pulmonary artery, right atrial and ventricular enlargement. Ventilation/ perfusion scans and CT angiography are useful in evaluating thromboembolic disease as the etiology of dyspnea and pulmonary hypertension. Finally, transthoracic echocardiography can be used to confirm hypertrophy of the right sided cardiac chambers and evaluate for structural defects, with the Doppler component of the echo serving as an important technique to evaluate $\mathrm{RV}$ systolic pressure. ${ }^{11}$

While non-invasive methods such as echocardiography can suggest elevated right- sided pressures, the gold standard for the diagnosis of $\mathrm{PH}$ remains the finding of elevated pressures in the pulmonary artery (PA) and on the right side of the heart by right heart catheterization. The clinical threshold for PH is crossed when the mean PA pressure exceeds $25 \mathrm{~mm} \mathrm{Hg}$ at rest or $30 \mathrm{~mm} \mathrm{Hg}$ during exercise. ${ }^{12}$

\section{Pulmonary Arterial Hypertension and Left Heart Failure}

Chronically elevated pulmonary venous pressures (reflected clinically as an elevation in pulmonary capillary wedge pressure [PCWP] on right heart catheterization) results from both systolic and diastolic heart failure and mitral valvular disease and is the most common cause of pulmonary hypertension. ${ }^{13}$, 14 Conversely, $\mathrm{PH}$ represents a common finding in $\mathrm{HF}$, and portends a poorer prognosis and worse outcomes.

The work of Butler and colleagues provides insight into the prevalence of $\mathrm{PH}$ in a cohort of patients with advanced HF undergoing evaluation for heart transplantation. ${ }^{15}$ They studied 320 patients undergoing exercise testing with invasive hemodynamic monitoring with systolic heart failure. Overall, this was a relatively ill population with a mean $\mathrm{VO}_{2} \max$ of $13 \mathrm{ml} / \mathrm{kg} / \mathrm{min}$. Only $28 \%$ of their patients had a normal pulmonary vascular resistance (PVR) of $<1.5$ woods 
units. The remaining $72 \%$ had elevated pulmonary vascular tone. Increased PVR negatively impacted peak exercise $\mathrm{VO}_{2}$, and other indices of rest and exercise hemodynamics. There was no association between EF, etiology of the underlying cardiomyopathy, or functional status (by NYHA class) and pulmonary vascular tone. Similarly, Ghio et al. found PH in over $60 \%$ of the patients that they studied. ${ }^{3}$ While abnormal pulmonary vascular tone and $\mathrm{PH}$ are common in patients with systolic heart failure, clinical characteristics do not predict the likelihood of developing PH.

More recently, the entity of heart failure with preserved $\mathrm{EF}$ (HFpEF), which accounts for nearly half of HF cases in the US, has received considerable attention. PH also appears to be a common hemodynamic finding in this group as well. In a population of HFpEF patients in Olmstead County, Minnesota, PA systolic pressure (PASP) and PCWP were estimated from echocardiography and compared to a control population without HF. ${ }^{16}$ While $\mathrm{PH}$ (defined here as PASP > $35 \mathrm{~mm} \mathrm{Hg}$ ) was diagnosed in $8 \%$ of the control group, $83 \%$ of the HFpEF group had elevated PA pressures. The median value in the hypertensive control group without HF was $28 \mathrm{~mm} \mathrm{Hg}$ while it was $48 \mathrm{~mm} \mathrm{Hg}$ the HFpEF group. Like systolic HF, PASP did correlate with pulmonary venous pressures as determined by PCWP in HFpEF. PH also appears to impact survival when present in $\mathrm{HFpEF}$, as the presence of $\mathrm{PH}$ was significantly associated with increased mortality. Hence, $\mathrm{PH}$ is both a prevalent comorbidity and poor prognostic finding in HF with either preserved or impaired LV systolic function.

PH and abnormal pulmonary vascular tone may impact HF by affecting RV function. The importance of RV performance in predicting functional capacity and survival in heart failure was established by Di Salvo and colleagues who studied exercise capacity in patients with advanced HF.17 Specifically, while LVEF predicts prognosis in HF, they found no association between LVEF and exercise capacity as determined by peak oxygen consumption. However, exercise capacity did correlate with RVEF. Furthermore, better RVEF was a significant predictor of survival in their advanced HF population. Ghio and colleagues examined the relationship between PA pressures and RV performance. ${ }^{3}$ Their analysis demonstrated a significant inverse relationship between RVEF and PA pressures, although they do point out a number of clinically relevant exceptions to this finding (e.g. normal PA pressures with RV dysfunction and $\mathrm{PH}$ with preserved RVEF). The combination of $\mathrm{PH}$ and HF is associated with an especially poor prognosis in the setting of concomitant $R V$ dysfunction. The authors speculate that the loss of $\mathrm{RV}$ performance may represent a relatively late finding in the setting of increased RV afterload and $\mathrm{PH}$, and that compromised RVEF may be a surrogate marker for the chronicity of HF. This remains speculative and the determinants of RV compromise in the setting of $\mathrm{HF}$ and $\mathrm{PH}$ remain unknown.

Recent studies support the notion that selective RV afterload reduction using strategies which decrease PVR and treat PH may be beneficial in HF. Inhaled NO, a pulmonary specific vasodilator, has been shown to effectively decrease PVR in patients with HF without lowering SVR or significant hypotension. ${ }^{18}$ Koelling et al. studied the impact of inhaled NO on exercise capacity in patients with severe HF. ${ }^{19}$ In patients with elevated PA pressures, exercise capacity increased by $22 \%$ with treatment. Importantly, selective pulmonary vasodilation and RV afterload reduction did not improve peak $\mathrm{VO}_{2}$ in patients without $\mathrm{PH}$. Thus inhaled $\mathrm{NO}$ ameliorates exercise capacity only in those patients with $\mathrm{PH}$.

While administration of inhaled NO is not practical chronically, other strategies to augment the effects of NO and which preferentially reduce PVR have been attempted in HF. Specifically, pharmacological agents such as sildenafil and tadalafil potentiate the endogenously produced NO by inhibiting type 5 phosphodiesterase (PDE5), resulting in intracellular accumulation of cGMP. Acutely, a single dose of sildenafil has been shown to decrease PVR and PA pressures preferentially, compared to the systemic circulation, both at rest and with exercise in patients 
with NYHA class III HF and PH. ${ }^{20}$ Moreover, the improvement in hemodynamics and measured peak oxygen consumption appears to be durable and generalizable to other indices of functional capacity. Lewis and colleagues studied patients with systolic HF on optimal medical therapy with $\mathrm{PH}$ and randomized them to chronic treatment with either sildenafil or placebo.21 Following 12-weeks of treatment, those patients receiving sildenafil had significantly improved exercise time, $\mathrm{VO}_{2} \max , 6$ minute walk distance, and $\mathrm{HF}$ symptom scores. These findings have been substantiated in other trials of PDE5 inhibition in HF. ${ }^{22,23}$ Thus, decreasing pulmonary vascular tone and treating PH in HF with PDE5 inhibition appears to offer beneficial effects in terms of hemodynamics, symptoms of HF, and functional capacity. None of these studies has yet to be sufficiently powered nor performed for sufficient duration to assess whether PDE5 inhibition might also impact survival in HF.

While studies of sildenafil-induced RV afterload reduction may provide enthusiasm for therapeutic strategies to treat $\mathrm{PH}$ and $\mathrm{HF}$, earlier trials using the pulmonary vasodilators epoprostenol and endothelin antagonists in HF did not achieve positive primary endpoints,

24-27 raising the possibility that the functional benefits of inhaled NO and PDE5 inhibition may not result purely from the hemodynamic effects of these agents. Instead, activation of the NO and cGMP signaling may have direct myocardial effects that at least in part may explain some of the beneficial effects of these agents. ${ }^{28}$ A more detailed understanding of the basic biology of PH may help define the advantages and pitfalls as well as help develop novel treatment approaches.

\section{The Biology of Pulmonary Hypertension}

Primary PAH is a relatively rare disorder with an incidence of 1-2 cases per million in the US population, ${ }^{6}$ but may offer insights into the etiology of more general diathesis towards aberrant pulmonary vascular responses in secondary $\mathrm{PH}$ such as that encountered in HF. Familial PH is an autosomal dominant disease with low penetrance; only $10-20 \%$ of patients harboring a mutation exhibit the overt disease phenotype. ${ }^{7}$

The diathesis to $\mathrm{PH}$ appears to vary based on environmental and genetic factors. Acquired disorders and exposures serve as triggers for PH including appetite suppressants (derivatives of fenfluramine and other anorexigens), toxins, and infection (e.g. HIV, reviewed elsewhere29). However, only a small minority of individuals exposed to environmental triggers eventually develop PH suggesting that the acquired exposure may serve as a trigger of a genetic susceptibility. Gender clearly exerts an influence on the diathesis to PH; women are diagnosed $2-5 \times$ as often as men.

While there are a number of diverse causes of $\mathrm{PH}$, shared pathological findings are identified in lungs of affected patients, including a) thickening of the walls of small pulmonary arteries with concomitant neointima formation and smooth muscle cell (SMC) proliferation in large and small pulmonary arteries, b) the presence of plexiform endothelial cell (EC) lesions characterized by capillary-like channels near pulmonary arterioles (200-400 $\mathrm{mM}$ in diameter), and c) the presence of thrombosis in situ. Tuder, Voelkel and their colleagues have reported that these plexiform lesions are characterized by proliferating ECs ${ }^{30}$ and the abundant expression of angiogenesis-related molecules.31 These investigators have also reported that ECs in plexiform lesions of primary $\mathrm{PH}$ patients are monoclonal, whereas lesions in secondary PH patients, while present are not monoclonal.32 Similarly, because in patients with PH associated with anorexigen use had monoclonal populations of ECs in plexiform lesions, Tuder and colleagues have suggested that anorexigens may serve as an environmental co-factor that precipitates PAH in susceptible individuals. 33 


\section{The role of BMP/BMPR2 signaling in disease pathogenesis}

The existence of familial forms of PH has offered a unique opportunity to define the cause of at least one form of pulmonary vascular disease. Using unbiased genetic approaches mutations in the Bone Morphogenetic Protein (BMP) type 2 receptor (BMPR2) gene have been identified as the cause of approximately one third of familial PH. ${ }^{34-} 36$ BMPR 2 mutations characterized to date suggest that haploinsufficiency may be the primary mechanism of action in a proportion of these cases, 37 but detailed studies in tractable animal models will be required to establish this formally. Of note, BMPR2 mutations also may have more pleiotropic cardiovascular effects than has been realized. In a detailed re-examination of families with PAH, Newman and colleagues were able to establish that several families that were previously thought to be distinct were in fact distantly related and that several family members also harbored congenital cardiac abnormalities or developed cardiomyopathy.38 Thus in addition to the role in $\mathrm{PH}$, heritable abnormalities in BMPR2 may also be associated with congenital heart disease and cardiomyopathy.

TGF- $\beta$ family signal transduction has further been implicated in other genetically mediated causes of PH in a separate but related condition Hereditary Hemorrhagic Telangiectasia (HHT). HHT is caused by mutations in ACVRLK1/ALK1, a type I TGF- $\beta$ receptor, and Endoglin, a TGF superfamily ligand. ${ }^{39}, 40$ Importantly these same pathways have been implicated in secondary forms of PH. Expression of BMPR2 is diminished in patients with PH: BMPR2 transcript is downregulated in the endothelium of patients with $\mathrm{PH}$ who do not harbor a mutation in the gene. Acquired forms of PH have also been associated with attenuation of the BMPR2 co-receptor ALK3/BMPR1a, which may be mediated via angiopoietin-1.41

\section{BMPR2 signal transduction}

BMPs belong to a large family of proteins related to TGF- $\beta$. Proteins in this family have effects on a variety of cell types depending on the cell environment and developmental stage. The TGF-b family of peptides can modulate the function of vascular cells (ECs and SMCs) including proliferation, migration, apoptosis, and secretion of extracellular cell matrix. BMPs are known to inhibit vascular SMC proliferation, ${ }^{42,43}$ to stimulate vascular SMC migration 44 and to inhibit neointima formation in balloon-injured rat carotid arteries. 43

TGF- $\beta$ family members bind to two different types of cell-surface receptors, referred to as type I and type II, both of which have intracellular serine-threonine kinase domains (reviewed elsewhere45). Upon ligand binding, type II receptors complex with type I receptors leading to type I receptor phosphorylation and activation. The activated type I receptors subsequently phosphorylate receptor-regulated Smad proteins (R-Smads) that interact with commonmediator Smads (Co-Smads) leading to modulation of gene transcription (Smad-dependent signaling). TGF- $\beta$ and BMPs have also been shown to activate MAP kinases including ERK, SAPK/JNK, and p38 (Smad-independent signaling). As with all type 2 BMP receptors, BMPR2 consists of a ligand-binding (extracellular) domain, a transmembrane domain, a serine/ threonine kinase domain, and a C-terminal cytoplasmic tail (a shorter splice variant also has been found in humans).

In all mammals, despite the large number of BMP ligands, there is a limited repertoire of type I and type II BMP receptors. Multiple combinations of type I and type II receptors create ligandbinding preference for specific ligands, but also afford receptor redundancy within the same class of receptors. BMP binding activates a subset of R-Smads (Smad1, Smad5, and Smad8) that together with the Co-Smad (Smad-4) and other transcription factors leads to BMPresponsive gene transcription. BMP (and TGF- $\beta$ ) signaling can be modulated by inhibitory Smads (I-Smads: Smad6 and Smad7) which compete with R-Smads for activated Type I 
receptors, and whose expression can be induced by TGF- $\beta$ or BMPs in a negative feedback loop.

Abundant evidence has demonstrated that TGF- $\beta$ /BMP signaling is required for the normal development in a number of vertebrate model organisms including chicken, mouse, frog and zebrafish in general and within the cardiovascular system specifically. BMPs can induce the expression of cardiac transcription factors such as Nkx2.5, GATA4, and TBX2 and 3.46,47 A variety of cardiac phenotypes have been reported in mice carrying targeted deletions of the genes encoding members of the TGF- $\beta$ /BMP family including BMP2, 4, 5/7, 6/7, 10, and TGF$\beta 2 .{ }^{48}$ Investigations in Xenopus indicate that BMP signaling is required for late manifestation of cardiac development but not for early markers of cardiac specification. ${ }^{49}$ Less is known regarding the contribution of specific receptors for BMP ligands and the roles played in cardiovascular development.

\section{Signaling Defects observed with BMPR2 mutations}

As reviewed above, signal transduction through BMPR2 is initiated by ligand binding to a receptor and activation of Smad-dependent and -independent intracellular signaling events. Though a relatively restricted set of type I and II receptors are known, heterodimerization enables potential combinatorial interactions between subunits. Hence rather than interrupting BMP signaling altogether, nullification of one type II receptor may instead shift the balance of signaling through other receptor subtypes.

Yu et al. investigated the impact of the loss of BMPR2 in pulmonary artery SMCs in vitro. ${ }^{50}$ Using cre-lox ex vivo inactivation as well as siRNA inactivation, they showed that while some BMP ligands appeared to have attenuated intracellular signaling via the classic SMAD-1/5/8 pathway, others (specifically BMP6 and BMP7) exhibited augmented signaling through alternate usage of the ActR-2a receptor. This suggests that the molecular defect in PH may result in augmented rather than attenuated BMP signaling. However, it is not clear whether Smad activity is increased or decreased in vivo with $\mathrm{PH}$.

\section{Animal Modeling of PH with BMPR2}

Transgenic mouse models have been used to dissect the contribution made by BMPR2 in development. Knockout of both BMPR2 alleles demonstrated that it is required for early development and led to complete involution and loss by embryonic day 9.5. Histological analysis of homozygous embryos revealed lack of mesoderm formation.51 Mice heterozygous deficient for BMPR2 while grossly normal, exhibit increased mean pulmonary arterial pressure and pulmonary vascular resistance compared with their wild-type littermates. Quantitative histological analysis reveals that heterozygous mice have increased wall thickness in muscularized pulmonary arteries ( $<100$ mum in diameter) and an increased number of alveolarcapillary units compared to wild-type mice.52 These histological findings parallel several of the pathological findings found in patients with PH. Furthermore, under conditions of inflammatory stress, heterozygous mice are more likely to develop increased right sided pressures and increased pulmonary vascular remodeling consistent with the observation that environmental factors can exacerbate a genetic diathesis to PH.53 Finally, transgenic mice with expression of a dominant negative (dn) BMPR2 in SMCs only, have histological findings of intimal proliferation and increased mural thickness in pulmonary arterioles.54 Interestingly, the alveolar/capillary ratio was unchanged and abnormalities were not observed in the smallest vessels.

Thus, BMPR2 is absolutely required in mammalian development. Germline heterozygous deficiency (i.e. in all tissues) phenocopies many aspects of PH. Familial PH results from germline transmission to all cells rather than mosaic loss in one cell type, and observational in 
situ data suggests that $\mathrm{PH}$ is associated with greater loss of transcript in vascular ECs rather than other cell types. Tissue specific interruption in the SMC of transgenic mice leads only to partial recapitulation of the observed pathological deficits in $\mathrm{PH} .{ }^{54}$ Conditional deletion in other tissues with murine transgenics is an active area of investigation and is anticipated to provide new insights into the ways that BMP signaling is involved in the vascular abnormalities underlying PH.

These studies highlight the emerging understanding that the pathophysiologic abnormalities of PH may have their origin during ontogeny. Animal models such as transgenic mice as well as other vertebrate developmental systems should provide a suitable platform for discovering the molecular and cellular alterations which give rise to the structural and functional defects in both primary and acquired forms of $\mathrm{PH}$ as is seen in HF. The detailed exploration of these experimental systems will provide the opportunity to integrate the basic discoveries with the clinical observations and trial data reviewed earlier and inform strategies to treat the spectrum of pulmonary hypertensive diseases.

\section{Acknowledgments}

Dr. Shin receives research support from the NIH.

\section{References}

1. Lloyd-Jones DM, Larson MG, Leip EP, et al. Lifetime risk for developing congestive heart failure: the Framingham Heart Study. Circulation 2002;106:3068. [PubMed: 12473553]

2. Lloyd-Jones D, Adams R, Carnethon M, et al. Heart disease and stroke statistics -- 2009 update: a report from the American Heart Association Statistics Committee and Stroke Statistics Subcommittee. Circulation 2009;119:480. [PubMed: 19171871]

3. Ghio S, Gavazzi A, Campana C, et al. Independent and additive prognostic value of right ventricular systolic function and pulmonary artery pressure in patients with chronic heart failure. J Am Coll Cardiol 2001;37:183. [PubMed: 11153735]

4. Gavazzi A, Ghio S, Scelsi L, et al. Response of the right ventricle to acute pulmonary vasodilation predicts the outcome in patients with advanced heart failure and pulmonary hypertension. Am Heart J 2003;145:310. [PubMed: 12595849]

5. Simonneau G, Galie N, Rubin LJ, et al. Clinical classification of pulmonary hypertension. J Am Coll Cardiol 2004;43:5S. [PubMed: 15194173]

6. Rubin LJ. Primary pulmonary hypertension. N Engl J Med 1997;336:111. [PubMed: 8988890]

7. Farber HW, Loscalzo J. Pulmonary arterial hypertension. N Engl J Med 2004;351:1655. [PubMed: 15483284]

8. Fishman AP. Clinical classification of pulmonary hypertension. Clin Chest Med 2001;22:385. [PubMed: 11590835]

9. Rich S, Dantzker DR, Ayres SM, et al. Primary pulmonary hypertension. A national prospective study. Ann Intern Med 1987;107:216. [PubMed: 3605900]

10. Leuchte HH, Holzapfel M, Baumgartner RA, et al. Characterization of brain natriuretic peptide in long-term follow-up of pulmonary arterial hypertension. Chest 2005;128:2368. [PubMed: 16236896]

11. Runo JR, Loyd JE. Primary pulmonary hypertension. Lancet 2003;361:1533. [PubMed: 12737878]

12. Rubin LJ. Primary pulmonary hypertension. Chest 1993;104:236. [PubMed: 8325077]

13. Rich S, Rabinovitch M. Diagnosis and treatment of secondary (non-category 1 ) pulmonary hypertension. Circulation 2008;118:2190. [PubMed: 19015413]

14. Oudiz RJ. Pulmonary hypertension associated with left-sided heart disease. Clin Chest Med 2007;28:233. [PubMed: 17338938]

15. Butler J, Chomsky DB, Wilson JR. Pulmonary hypertension and exercise intolerance in patients with heart failure. J Am Coll Cardiol 1999;34:1802. [PubMed: 10577573] 
16. Lam CS, Roger VL, Rodeheffer RJ, et al. Pulmonary hypertension in heart failure with preserved ejection fraction: a community-based study. J Am Coll Cardiol 2009;53:1119. [PubMed: 19324256]

17. Di Salvo TG, Mathier M, Semigran MJ, et al. Preserved right ventricular ejection fraction predicts exercise capacity and survival in advanced heart failure. J Am Coll Cardiol 1995;25:1143. [PubMed: 7897128]

18. Semigran MJ, Cockrill BA, Kacmarek R, et al. Hemodynamic effects of inhaled nitric oxide in heart failure. J Am Coll Cardiol 1994;24:982. [PubMed: 7930234]

19. Koelling TM, Kirmse M, Di Salvo TG, et al. Inhaled nitric oxide improves exercise capacity in patients with severe heart failure and right ventricular dysfunction. Am J Cardiol 1998;81:1494. [PubMed: 9645904]

20. Lewis GD, Lachmann J, Camuso J, et al. Sildenafil improves exercise hemodynamics and oxygen uptake in patients with systolic heart failure. Circulation 2007;115:59. [PubMed: 17179022]

21. Lewis GD, Shah R, Shahzad K, et al. Sildenafil improves exercise capacity and quality of life in patients with systolic heart failure and secondary pulmonary hypertension. Circulation 2007;116:1555. [PubMed: 17785618]

22. Behling A, Rohde LE, Colombo FC, et al. Effects of 5'-phosphodiesterase four-week long inhibition with sildenafil in patients with chronic heart failure: a double-blind, placebo-controlled clinical trial. J Card Fail 2008;14:189. [PubMed: 18381181]

23. Guazzi M, Samaja M, Arena R, et al. Long-term use of sildenafil in the therapeutic management of heart failure. J Am Coll Cardiol 2007;50:2136. [PubMed: 18036451]

24. Szokodi I, Piuhola J, Ruskoaho H. Endothelin receptor blockade and exacerbation of heart failure. Circulation 2003;107:e211. [PubMed: 12796421]

25. Anand I, McMurray J, Cohn JN, et al. Long-term effects of darusentan on left-ventricular remodelling and clinical outcomes in the EndothelinA Receptor Antagonist Trial in Heart Failure (EARTH): randomised, double-blind, placebo-controlled trial. Lancet 2004;364:347. [PubMed: 15276394]

26. Packer M, McMurray J, Massie BM, et al. Clinical effects of endothelin receptor antagonism with bosentan in patients with severe chronic heart failure: results of a pilot study. J Card Fail 2005;11:12. [PubMed: 15704058]

27. Califf RM, Adams KF, McKenna WJ, et al. A randomized controlled trial of epoprostenol therapy for severe congestive heart failure: The Flolan International Randomized Survival Trial (FIRST). Am Heart J 1997;134:44. [PubMed: 9266782]

28. Takimoto E, Champion HC, Li M, et al. Chronic inhibition of cyclic GMP phosphodiesterase 5A prevents and reverses cardiac hypertrophy. Nat Med 2005;11:214. [PubMed: 15665834]

29. Archer S, Rich S. Primary pulmonary hypertension: a vascular biology and translational research "Work in progress". Circulation 2000;102:2781. [PubMed: 11094047]

30. Tuder RM, Groves B, Badesch DB, et al. Exuberant endothelial cell growth and elements of inflammation are present in plexiform lesions of pulmonary hypertension. Am J Pathol 1994;144:275. [PubMed: 7508683]

31. Tuder RM, Chacon M, Alger L, et al. Expression of angiogenesis-related molecules in plexiform lesions in severe pulmonary hypertension: evidence for a process of disordered angiogenesis. J Pathol 2001;195:367. [PubMed: 11673836]

32. Lee SD, Shroyer KR, Markham NE, et al. Monoclonal endothelial cell proliferation is present in primary but not secondary pulmonary hypertension. J Clin Invest 1998;101:927. [PubMed: 9486960]

33. Tuder RM, Radisavljevic Z, Shroyer KR, et al. Monoclonal endothelial cells in appetite suppressantassociated pulmonary hypertension. Am J Respir Crit Care Med 1998;158:1999. [PubMed: 9847298]

34. Deng Z, Morse JH, Slager SL, et al. Familial primary pulmonary hypertension (gene PPH1) is caused by mutations in the bone morphogenetic protein receptor-II gene. Am J Hum Genet 2000;67:737. [PubMed: 10903931]

35. Lane KB, Machado RD, Pauciulo MW, et al. Heterozygous germline mutations in BMPR2, encoding a TGF-beta receptor, cause familial primary pulmonary hypertension. The International PPH Consortium. Nat Genet 2000;26:81. [PubMed: 10973254]

36. Thomson JR, Machado RD, Pauciulo MW, et al. Sporadic primary pulmonary hypertension is associated with germline mutations of the gene encoding BMPR-II, a receptor member of the TGFbeta family. J Med Genet 2000;37:741. [PubMed: 11015450] 
37. Machado RD, Pauciulo MW, Thomson JR, et al. BMPR2 haploinsufficiency as the inherited molecular mechanism for primary pulmonary hypertension. Am J Hum Genet 2001;68:92. [PubMed: 11115378]

38. Newman JH, Wheeler L, Lane KB, et al. Mutation in the gene for bone morphogenetic protein receptor II as a cause of primary pulmonary hypertension in a large kindred. N Engl J Med 2001;345:319. [PubMed: 11484688]

39. McAllister KA, Grogg KM, Johnson DW, et al. Endoglin, a TGF-beta binding protein of endothelial cells, is the gene for hereditary haemorrhagic telangiectasia type 1. Nat Genet 1994;8:345. [PubMed: 7894484]

40. Johnson DW, Berg JN, Baldwin MA, et al. Mutations in the activin receptor-like kinase 1 gene in hereditary haemorrhagic telangiectasia type 2. Nat Genet 1996;13:189. [PubMed: 8640225]

41. Du L, Sullivan CC, Chu D, et al. Signaling molecules in nonfamilial pulmonary hypertension. N Engl J Med 2003;348:500. [PubMed: 12571257]

42. Dorai H, Vukicevic S, Sampath TK. Bone morphogenetic protein-7 (osteogenic protein-1) inhibits smooth muscle cell proliferation and stimulates the expression of markers that are characteristic of SMC phenotype in vitro. J Cell Physiol 2000;184:37. [PubMed: 10825232]

43. Nakaoka T, Gonda K, Ogita T, et al. Inhibition of rat vascular smooth muscle proliferation in vitro and in vivo by bone morphogenetic protein-2. J Clin Invest 1997;100:2824. [PubMed: 9389748]

44. Willette RN, Gu JL, Lysko PG, et al. BMP-2 gene expression and effects on human vascular smooth muscle cells. J Vasc Res 1999;36:120. [PubMed: 10213907]

45. Miyazono K, Kusanagi K, Inoue H. Divergence and convergence of TGF-beta/BMP signaling. J Cell Physiol 2001;187:265. [PubMed: 11319750]

46. Yamada M, Revelli JP, Eichele G, et al. Expression of chick Tbx-2, Tbx-3, and Tbx-5 genes during early heart development: evidence for BMP2 induction of Tbx2. Dev Biol 2000;228:95. [PubMed: 11087629]

47. Brown CO 3rd, Chi X, Garcia-Gras E, et al. The cardiac determination factor, Nkx2-5, is activated by mutual cofactors GATA-4 and Smad1/4 via a novel upstream enhancer. J Biol Chem 2004;279:10659. [PubMed: 14662776]

48. Zhao GQ. Consequences of knocking out BMP signaling in the mouse. Genesis 2003;35:43. [PubMed: 12481298]

49. Walters MJ, Wayman GA, Christian JL. Bone morphogenetic protein function is required for terminal differentiation of the heart but not for early expression of cardiac marker genes. Mech Dev 2001;100:263. [PubMed: 11165483]

50. Yu PB, Beppu H, Kawai N, et al. Bone morphogenetic protein (BMP) type II receptor deletion reveals BMP ligand-specific gain of signaling in pulmonary artery smooth muscle cells. J Biol Chem 2005;280:24443. [PubMed: 15883158]

51. Beppu H, Kawabata M, Hamamoto T, et al. BMP type II receptor is required for gastrulation and early development of mouse embryos. Dev Biol 2000;221:249. [PubMed: 10772805]

52. Beppu H, Ichinose F, Kawai N, et al. BMPR-II heterozygous mice have mild pulmonary hypertension and an impaired pulmonary vascular remodeling response to prolonged hypoxia. Am J Physiol Lung Cell Mol Physiol 2004;287:L1241. [PubMed: 15286002]

53. Song Y, Jones JE, Beppu H, et al. Increased susceptibility to pulmonary hypertension in heterozygous BMPR2-mutant mice. Circulation 2005;112:553. [PubMed: 16027259]

54. West J, Fagan K, Steudel W, et al. Pulmonary hypertension in transgenic mice expressing a dominantnegative BMPRII gene in smooth muscle. Circ Res 2004;94:1109. [PubMed: 15031260] 